\title{
EFFECT OF REHABILITATION REGIMEN FOR IMPROVING FUNCTIONAL OUTCOME AFTER TOTAL HIP REPLACEMENT SURGERY IN MANSOURA UNIVERSITY HOSPITALS \\ ${ }^{1}$ Abeer Mohammed el metwaly, ${ }^{2}$ Amany Mohammed Sheble and \\ ${ }^{3}$ Waffa Ismail Salama, Mostafa Abd EI Khalk \\ ${ }^{1}$ Nurse specialist, Faculty of Nursing, ${ }^{2}$ Prof.of Medical-Surgical Nursing Department, Faculty of Nursing, ${ }^{3}$ prof. of Medical-Surgical Nursing, Faculty of Nursing, prof of orthopedic, Faculty of medicine- Mansoura University \\ E-mail of the corresponding author: abofatma777@yahoo.com
}

Abstract:

Background Total hip replacement surgery has become the treatment of choice for patients suffering from rheumatoid arthritis and osteoarthritis of the hip. The Aim of the study: assess the effect of rehabilitation regimes on improving function outcome for patients undergoing total hip replacement surgery. Research design: A quasi-experimental design had utilized in this study. Study setting this study was carried out in the Orthopedic Departments at main Mansoura university hospital. Subjects Purposive sample including all available patients who admitted to the orthopedic department during six months and treated with total hip replacement (66 patient), and divided into two groups study and control group study tools: Two tools were utilized. Tool (1) Patients Adjustment Tool: This tool was used to measure the effects of the applied regimes on patients' post-hospital functional outcome after total hip replacement. It contains 6 parts (2) The Rehabilitation Program: This program planned to cover knowledge and practice for total hip replacement patients aiming to improve their functional outcome. Results: It can be noticed that the mean age of subjects was 41 years for the study group and 46 years for the control groups. In relation to sex Females, patients represented the higher percentage $(60 \%)$ and $(63 \%)$ for both the study and control groups respectively. It was found that there was a significant difference between study and control groups in relation to a post-discharge period ( $\left.\mathrm{p}<0.001^{*}\right)$. Also, it showed a significant difference between preoperative and post-discharge function outcome in the study and control groups Paired t-test $(\mathrm{P}$ value $)<0.001 *<0.001 *$ Conclusion: the rehabilitation program that implemented to study group patients had a positive effect on functional outcome. Recommendations: rehabilitation program should be started on the first day of patient admission to hospital, a Simple booklet written in the Arabic language should be available for all patients undergoing total hipreplacement.

Key words: Total hip replacement, rehabilitation program, function out com

\section{Introduction:}

Total hip replacement surgery (T.H.R) has become a treatment of choice for patients suffering from rheumatoid arthritis and osteoarthritis and osteoarthritis of the hip ${ }^{(1)}$. Treatment strategies for total hip replacement pain have usually involved conservative measurement (analgesia, exercise, education, weight reduction) with surgical intervention THR being the most effective treatment for the end stage of disease ${ }^{(2)}$.Especially, if the destructive process involves both the acetabulum and femoral head, THR provide those patients with new prosthetic materials. THR 
consider one of the most frequently performed major orthopedic surgeries. Over the past decade, in most Organization for Economic Cooperation and Development countries, the prevalence of THR had rapidly increased ${ }^{(3)}$. It was in the United States (2010) was $0.80 \%$ Incidence for THR was greater among female than male and with aging, as at eighty years reaching $5.26 \%$. This prevalence corresponded to 2.5 million patients (1.4 million female and 1.1 million male) with THR and 5 million patients. Secular trends stated a significant rise in number over time and a shift to younger ages ${ }^{(4)}$. Although there are indications for total hip replacement in younger people especially those with multiple joint involvements from a systemic disorder such as rheumatoid arthritis or systemic lupus erythematosus, the procedure generally is reserved for old individual and those with relatively sedentary lifestyle. Other indications are the recons traction of dysplastic hip joints or following bone defects caused by accidents or diseases, avascular necrosis (necrosis of bone tissue due to interruption of blood supply), and other rare diseases that compromise hip function (5). Contraindications for THR include conditions that would limit or prevent the success of the procedure. The main absolute contraindications are an active infection (includes localized septic arthritis and osteomyelitis as well as regional and systemic infection elsewhere in the body), immaturity, bone stock inadequate to support the device due to severe osteoporosis or severe osteopenia, and Patient inability to follow preoperative and postoperative instructions ${ }^{(6)}$. Two general goals should be kept in mind during the rehabilitation that follows hip surgery. The first goal is to prevent or avoid complications and the second is to maximize the outcome of surgical intervention. To accomplish these goals, patients should have a thorough explanation of what a "total hip" is and what the plan of treatment and care will be like following the operation. in the hospital, an excellent teaching tool for both the patient and family' is a photograph album containing snapshots of people, equipment, and procedures involved in the entire program, along with written wards providing explanations. Moreover, simple printed instructional materials can be retained by the patient and reviewed in a leisurely fashion at home as reinforcing materials. ${ }^{(7)}$ .Ideally, rehabilitation should begin before the operation. Nurses should be more attuned to patients' level of fear, anxiety and adapt preoperative instructions accordingly. They should focus on a procedural aspect of care when individuals display lower levels of fear and anxiety and focus on psychological content when patient display high level of fear and anxiety. Such a preoperative instruction program would be congruent with the nursing process, as it is based on initial assessment and followed by analysis of the patient's needs, planning, and implementation of the instruction, and evaluation of the teaching's effectiveness. ${ }^{(8)}$

\section{I - Aim of the study.}

The aim of the study was to assess the effect of rehabilitation regime on improving function outcome for patients undergoing total hip replacement surgery.

\section{II- Research hypnosis.}

The rehabilitation regimen will have the positive effect on improving function outcome of patients after total hip replacement surgery than patients who did not receive the rehabilitation regimen.

\section{III- Material and methods \\ Research design:}

A quasi-experimental design had utilized in the study.

\section{(1) Technical design:}

The technical design for the study includes research setting of the study, 
subjects of the study and tools for data collection.

\section{Setting:}

This study was carried out in the Orthopedic Departments at main Mansura university hospital and divided into two departments one for males and other for females each department contains 20 beds

\section{Subjects:}

Purposive sample included all available patients that admitted to orthopedic department during six months and treated with total hip replacement there are (66 patient), they were divided into two groups study group and control group and should be full fill the following criteria

\section{I- Inclusion criteria.}

- Alert and able to communicate

- Patient age from 20year to 60year-old.

- Both six

II -Exclusion criteria.

- Have previous hip surgery.

- Have visual or auditory impairment.

- The selected patients will be divided equally into control and study group.

\section{Tools of the data collection:}

The data was collected through utilizing the following tools

\section{(1) Patients Adjustment Tool:}

This tool had taken from ${ }^{(9)}$ and used to measure the effects of the applied regime on patients' post-hospital functional outcome after total hip replacement. It includes the following parts:

\section{Part one:}

1- Socio-demographic data including; patient name, age, sex, level of education, occupation, admission date, operational date hospital stay and discharge date.
2- Medical data including patient general assessment e.g. diagnosis, history of another disease and family history.

\section{Part two:}

capability index:-

It includes Tow functional

\section{1-The Objective Functional Capability Index (OFCI}

It is observation sheet consisted of four sections: assessment of the strength of affected/operated leg, assessment of active movement of a hip joint, assessment of ability to walk, and assessment of stair management ability (Preoperative and post-discharge). The score was distributed as follows: (zero) if the patient is unable to move his leg, (one) if minimal contraction can be palpated, (two) if patient can move his leg but not against gravity, (three) if the patient's leg permits full range of motion (R.O.M.) against gravity but then cannot sustain resistance, (four) if patient's leg permits full ROM against gravity and can make little of resistance, (five) for normal strength.

\section{2-The Subjective Functional Capability} Index (SFCI)

It consists of 2 sections: (preoperative and post-discharge).

\section{(a) Section one:}

A checklist was designed to gather information about patients' self-assessment of their ability to perform the following indoor activities of daily living: dressing, undressing, bathing, putting on shoes, tying shoelaces, preparing meals, and house chores. By the help of the investigator, the patient asked to choose or check on a four-point Likert scales the ability to perform the activities using interview guide

\section{(b) Section two:}

A checklist was designed to gather information about patients' self-assessment of their degree of performing the following outdoor activities of daily living: getting in 
the car, getting out of a car, getting in the chair, getting out of a chair, walking, walking up stairs, walking downstairs and shopping. Each activity was scored separately as follows: (four) performed with great ease; (three) some ease, (two) some difficulty, (one) great difficulty.

\section{Part three:}

\section{The Subjective Psychosocial} Capability Index (SPSCI):

It was an interview questionnaire used to assess the psychosocial well-being of the patients (preoperative and postdischarge), The questionnaire contained 7 items, three of these items assessed psychological status of the patient and the other four items assessed his/her social status. Psychological status items include the feeling of tiredness, frustration, and anxiety. The patients were asked to choose or check one frequency from not at all, sometimes and always responses. Scores of two, one and zero were allotted to these frequencies respectively.

Social status items include: seeing friends in a home, going do visits, going to clubs and hobbies. The patients were asked to choose or check one from improved, not changed and deteriorated responses. The scores assigned to these responses were two, one and zero respectively.

\section{Part four:}

The Knowledge Test of Post-Hip Arthroplast Complications (KTPHAC)

It is an interview schedule designed to determine patients' information of post hip replacement complications (preoperative and pre discharge). It was consisted of nine queries, testing the knowledge of potential postoperative complications such as pulmonary embolisms, prosthetic dislocation, deep wound infection and venous thrombosis. Patients were asked to choose or check one from yes, no or don't know responses for each of the first five questions. For the other four questions, the patients were asked to choose or place a check mark on the best answer. The maximum score allotted to this knowledge test was nine points.

\section{Part five:}

The Perceived Preparedness for Discharge Scale (PPFDS).

It is an interview schedule which encompasses 8 questions used to collect information on patients' perception of readiness for discharge from hospital (predischarge). Patients were asked to choose or check one from yes or no responses for each question.

Part six:

\section{The Patient complaint Behavior} Index (CBI)

It is an observation checklist which consisted of 6 items used to observe the patients' accuracy in performing selected activities such as, sitting, standing and getting in and out of bed (postoperative). The observation checklist included two columns upon which patients' performances were checked by the researcher using: yes and no, they scored one and zero respectively. Total observation scores yielded 6 points.

\section{(2) The Rehabilitation Program:}

a) This program planned to cover knowledge and practice for total hip replacement patients aiming to improve their function out com. The content of the program was developed after reviewing the following related literature $e^{(\mathbf{1}, 2,10)}$ the content was translated into Arabic It included 3 sessions of patient teaching given to patients individual during pre-operative, postoperative and pre-discharge periods by means of verbal information, demonstration and pictures Simple 
anatomy of the hip and total hip replacement surgery.

b) Positioning in bed postoperatively and postoperative exercises.

c) Warning signs and symptoms of common complications following total hip replacement.

d) Performance of selected activities of daily living and instruction on safe methods of carrying out these activities.

e) Safe and proper use of different aids for walking, bathing, and dressing.

f) Post discharge exercises and hip precautions.

g) Expected stages of progress during the first six months postoperatively.

h) The potential impact of the outcome of the operation on the patients' psychosocial welfare, to prevent unrealistic expectations after the operation.

\section{Operational design:}

The operational design consists of the preparatory phase, content validity, pilot study, fieldwork, and limitation of the study.

\section{The preparatory phase:}

It includes reviewing of literature and research results related to total hip surgery rehabilitation needs and management approaches, using books, articles periodicals, and magazines to develop the study tools for data collection.

\section{Content validity:}

Test validity: It was done for the developed tool and the designed instructional guide to determine whether the tool covered the aim. This stage was developed by a jury of five experts (two assistant lectures from a faculty of nursing and three assistant professors from the faculty of nursing and one assistant lectures from the faculty of medicine, Mansoura University).

\section{Pilot study:}

The pilot study was carried out on six patients within the selected criteria to test the applicability and relevance of the tool, and test clarity of the designed questionnaire as well as to estimate the time needed to answer it, and then the necessary modification was done. These patients were excluded from the study

\section{Field Work:}

- Data collection for study was carried out in the period six-month started from January 2015 to Julay 2015

- The researcher introduced himself to the patient.

- Socio demographic patient data was obtained on the day of admission from all patients participating in the study.

- In the preoperative period, every patient (in both groups) was assessed for: a strength of affected leg, active movement of affected hip joint, walking ability and stair management ability by using the Objective Functional Capability Index. In addition, the researchers collected data on patients' subjective assessment of their capability of performing specific activities by using Subjective Functional Capability Index.

- Patients' assessment of their preoperative psychosocial well-being was collected by means of Subjective Psychosocial Capability Index. Every patient was interviewed preoperatively to answer questions concerning knowledge about post hip replacement complications. Patients in the control group only received the advice and support that were routinely given to total hip replacement patients by ward medical and nursing staff.

- Teaching to patients in the study group was given individually and in the patient ward through personal interview, within 30-60 minutes by using teaching methods for example ( 
discussion, demonstration and illustrated pictures) according to the following schedule:

- Simple information was given preoperatively related to the anatomy of hip, total hip replacement surgery, early signs and symptoms of postoperative complications, positioning in bed post-operatively, post-operative exercises and early signs and symptoms of postoperative complications.

\section{Ethical Consideration:}

1 Prior to the study, written consent will be obtained from each patient enrollment into the study, and after clarification the nature of the study.

2 Investigator emphasized participation is absolutely and confidential.

3 Anonymity, privacy, safety, and confidentiality will absolutely assure throughout the whole study.

4 Each participant has the right to withdraw from the study at any time. Patients were given the opportunity to ask any questions regarding the study. In addition, for educated patients, they were asked to read the instruction given carefully and answer the questionnaire. For illiterate patients, the researcher read the questionnaire and was marked on the answers that choose it.

5 The researcher started data collection following certain schedule of three days /week, from 9 am to $1 \mathrm{pm}$.

\section{(5) Statistical analysis:}

The collected data was organized, categorized, tabulated and statistically analyzed to evaluate the difference between the study and control group pre and post-program and to elicit some relations. The statistical analysis included percentage, mean, standard deviation (SD), t-test, paired t-test (p-value). The above-mentioned statistical techniques were obtained by using IBM compatible personal computer using the statistical package of social sciences SPSS version 12.

\author{
Also, statistical significance was \\ considered at: \\ - Not significant if $\mathrm{p}>0.05$ \\ - Significant if $\mathrm{p}<0.05$ \\ - High significant if $\mathrm{p}<0.01$
}

\section{Results:}

The data collected were analyzed statistically and the results are categorized into 6parts.

\section{Part I: Distribution of patients according to their socio demographic data.}

It can be noticed that the mean age of subjects was 41 years for the study group and 46 years for the control groups. In relation to sex Females, patients represented the higher percentage $(60 \%)$ and $(63 \%)$ for both the study and control groups respectively. In relation to occupation, it was found the majority of patients were house wife's constituted $46.7 \%$ of the study group and $56.7 \%$ of the control group. In relation to social status, most of them $(83.3 \%)$ of the patients in study group and control group were married. In Study and control group patients most of them diagnosed osteoarthritis as preoperative diagnosis about $90 \%$ and $70 \%$ respectively. At admission time more than half $(56.7 \%)$ of patients in study group and half of them $(50 \%)$ in control group had no coexistent disease. 
EFFECT OF REHABILITATION REGIMEN FOR etc ...

\begin{tabular}{|c|c|c|c|c|c|c|}
\hline $\begin{array}{c}\text { Socio demographic } \\
\text { data }\end{array}$ & \multicolumn{2}{|c|}{$\begin{array}{l}\text { Study group } \\
\quad(\mathbf{n}=\mathbf{3 0})\end{array}$} & \multicolumn{2}{|c|}{$\begin{array}{l}\text { Control group } \\
\quad(n=30)\end{array}$} & $\mathbf{T}$ & $\mathbf{P}$ \\
\hline \multirow[t]{2}{*}{ Age } & \multicolumn{2}{|c|}{$41.73 \pm 11.97$} & \multicolumn{2}{|c|}{$46.07 \pm 13.43$} & 1.319 & 0.192 \\
\hline & No & $\%$ & No & $\%$ & $\chi^{2}$ & $\mathbf{P}$ \\
\hline $\begin{array}{c}\text { Sex } \\
\text { Male } \\
\text { Female }\end{array}$ & $\begin{array}{l}12 \\
18\end{array}$ & $\begin{array}{l}40 \% \\
60 \%\end{array}$ & $\begin{array}{l}11 \\
19\end{array}$ & $\begin{array}{l}36.7 \% \\
63.3 \%\end{array}$ & 0.071 & 0.791 \\
\hline $\begin{array}{c}\text { Job } \\
\text { Housewife } \\
\text { Teacher } \\
\text { Employee } \\
\text { Worker } \\
\end{array}$ & $\begin{array}{l}14 \\
4 \\
3 \\
9\end{array}$ & $\begin{array}{c}46.7 \% \\
13.3 \% \\
10 \% \\
30 \%\end{array}$ & $\begin{array}{l}17 \\
2 \\
3 \\
8\end{array}$ & $\begin{array}{c}56.7 \% \\
6.7 \% \\
10 \% \\
26.7 \%\end{array}$ & 1.016 & 0.797 \\
\hline $\begin{array}{c}\text { Education } \\
\text { Literate } \\
\text { Primary } \\
\text { Preparatory } \\
\text { Secondary } \\
\text { Up moderate education } \\
\text { read and write } \\
\text { Academic }\end{array}$ & $\begin{array}{l}12 \\
3 \\
1 \\
9 \\
1 \\
0 \\
4\end{array}$ & $\begin{array}{c}40 \% \\
10 \% \\
3.3 \% \\
30 \% \\
3.3 \% \\
0 \% \\
13.3 \%\end{array}$ & $\begin{array}{l}14 \\
8 \\
0 \\
5 \\
1 \\
2 \\
0\end{array}$ & $\begin{array}{c}46.7 \% \\
26.7 \% \\
0 \% \\
16.7 \% \\
3.3 \% \\
6.7 \% \\
0 \%\end{array}$ & 10.569 & 0.103 \\
\hline $\begin{array}{c}\text { Marital status } \\
\text { Single } \\
\text { Married } \\
\text { Divorced } \\
\text { Widow }\end{array}$ & $\begin{array}{c}4 \\
25 \\
0 \\
1\end{array}$ & $\begin{array}{c}13.3 \% \\
83.3 \% \\
0 \% \\
3.3 \%\end{array}$ & $\begin{array}{c}4 \\
25 \\
1 \\
0\end{array}$ & $\begin{array}{c}13.3 \% \\
83.3 \% \\
3.3 \% \\
0 \%\end{array}$ & 2.0 & 0.572 \\
\hline $\begin{array}{c}\text { Diagnosis } \\
\text { Hip Fracture } \\
\text { O.A.HIP } \\
\text { Rheumatoid arthritis }\end{array}$ & $\begin{array}{c}0 \\
27 \\
3\end{array}$ & $\begin{array}{l}0 \% \\
90 \% \\
10 \%\end{array}$ & $\begin{array}{c}6 \\
21 \\
3\end{array}$ & $\begin{array}{l}20 \% \\
70 \% \\
10 \%\end{array}$ & 6.750 & $0.034 *$ \\
\hline
\end{tabular}

Figure 1: Assessment of patients walking ability of both study and control groups preoperatively and post-discharge.

This table shows assessment of patient's ability of both study and control groups preoperatively and post-discharge. The result revealed that more than one-third $(43.3 \%)$ of a patient in study groups and (40\%) of patients in control group could walk only with canes preoperatively. After discharge, this percentage decreased to( 33.3\%) in study groups and increase to $(50 \%)$ in control groups the result also Shaw that near to half $(46.7 \%)$ of study groups and $(23 \%)$ in control group walking with one cane less than one hours postoperatively. And (13.3\%) in study groups, $23.3 \%$ in control group able to walk only with crutches postoperatively. Also $6.7 \%$ and $3.3 \%$ in the study and control groups able to walk without the cane for short distance and with sever limp. The difference between preoperative and post-discharge in the study and control were significance in p-value $(00.02,00.01)$ 


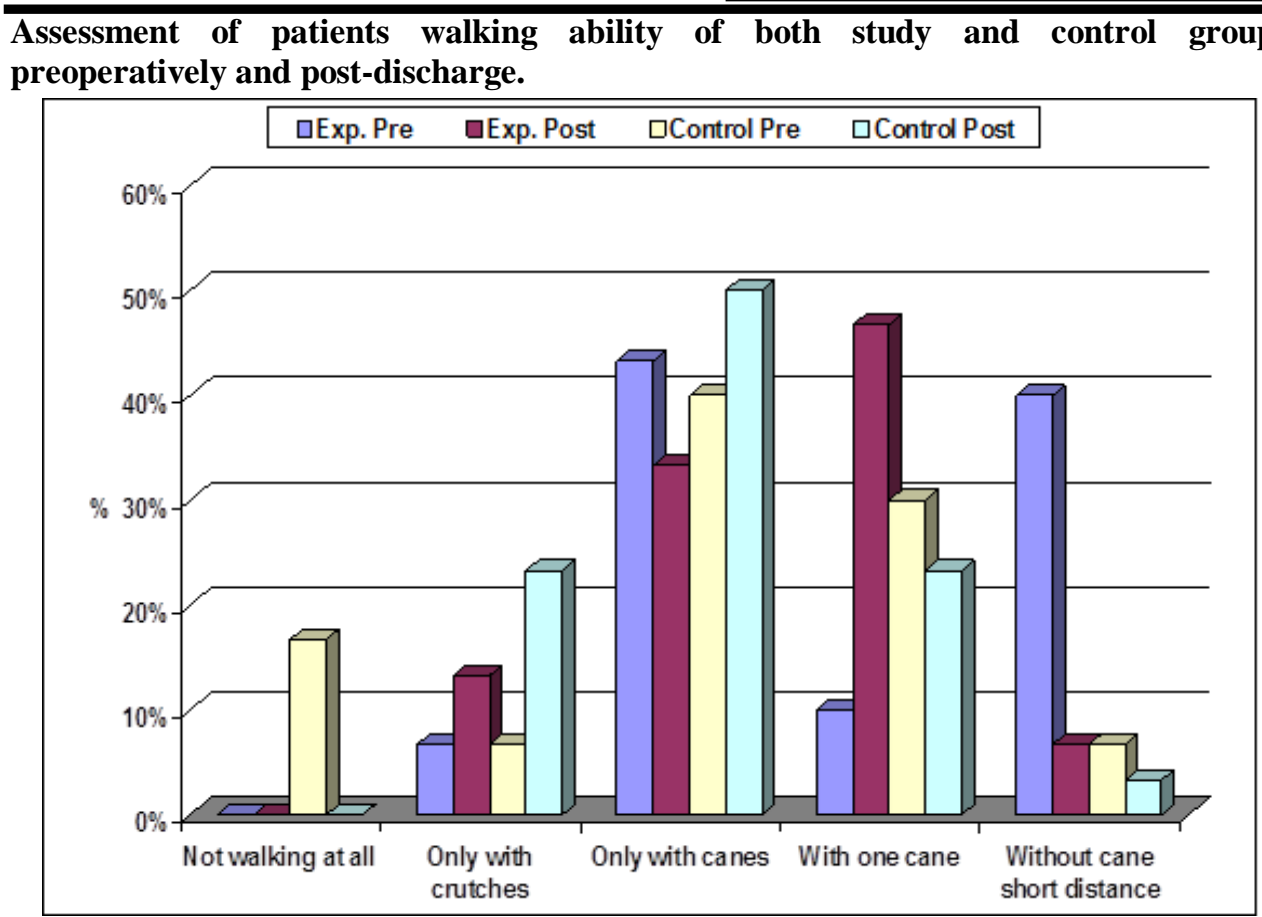

Figure (1)

Figure 2: Assessment of patient's ability to manage stairs preoperatively and postdischarge of both study and control groups.

This table show assessment of patient's ability to manage stairs preoperatively and postdischarge in both study and control groups. The findings indicated that none of the patients in control groups could walk up one flight of stairs with cane/crutches without difficulty and pain preoperatively and in study groups and only (13.3\%) could walk up one flight of stairs with cane/crutches without difficulty and pain preoperatively. After discharge, this percentage was increased to near to one-third (36.7\%) in control groups while it reached up to the majority of them $(73.3 \%)$ in a study group. Also half of them $(46.7 \%)$ in study group walk with cane/crutches and with a great deal of difficulty and pain and $36.7 \%$ in control group this percentage decreed to $14 \%$ in a study and $10 \%$ in control group. The difference between preoperative and post-discharge in the study and control group were significant ( $<0.001)$ respectively. 


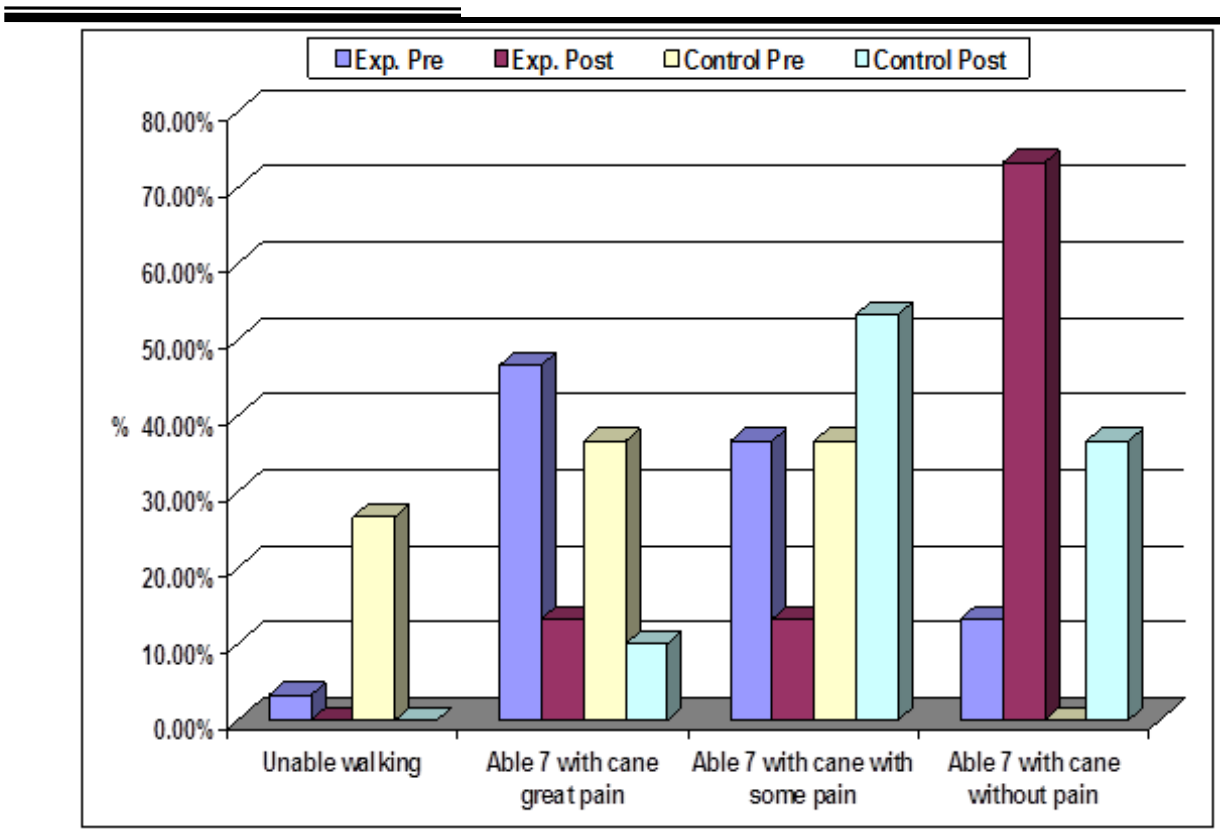

Figure 2 Assessment of patients ability to manage stairs preoperatively and postdischarge of both study and control groups.

Table (2): Mean score, stander deviation and statistical differences between both study and control groups regarding their ability to perform indoor activities of daily living.

Reveals mean score, stander deviation and statistical differences between both study and control groups regarding their ability to perform indoor activities of daily living. It was found that there was a significant difference between study and control groups in relation to a post-discharge period (Student's t-test ( $\mathrm{P}$ value) $0.003^{*}$. The table also showed the significant difference between preoperative and post-discharge period in the study and control groups Paired t-test $(\mathrm{P}$ value $)<0.001 *<0.001 *$ Significant $\mathrm{P}<0.05$

Table (2): Mean score, stander deviation and statistical differences between both study and control groups regarding their ability to perform indoor activities of daily living

\begin{tabular}{|c|c|c|c|}
\hline $\begin{array}{c}\text { Ability of performance } \\
\text { (ADL) }\end{array}$ & $\begin{array}{c}\text { Study } \\
(\mathbf{n = 3 0})\end{array}$ & $\begin{array}{c}\text { Control } \\
(\mathbf{n = 3 0})\end{array}$ & $\begin{array}{c}\text { Student's t-test } \\
\text { (P value) }\end{array}$ \\
\hline Preoperative & $13.57 \pm 4.76$ & $12.07 \pm 4.50$ & 0.215 \\
\hline Post-discharge & $21.43 \pm 4.17$ & $17.93 \pm 4.46$ & $0.003^{*}$ \\
\hline Paired t-test (P value) & $<0.001^{*}$ & $<0.001^{*}$ & \\
\hline
\end{tabular}

Table (3): Mean score, stander deviation and statistical differences between both study and control groups regarding their ability to perform outdoor activities of daily living.

Mean score, stander deviation and statistical differences between both study and control groups regarding their ability to perform outdoor activities of daily living. It was found that there was a significant difference between study and control groups in relation to a post- 
Abeer Mohammed el metwaly, et. al.

discharge period (Student's t-test $(\mathrm{P}$ value) $<0.001 *$. The table also showed significant difference between preoperative and post-discharge period in the study and control groups Paired t-test $(\mathrm{P}$ value $)<0.001 *<0.001 *$ Significant $\mathrm{P}<0.05$

Table (3): Mean score, stander deviation and statistical differences between both study and control groups regarding their ability to perform outdoor activities of daily living

\begin{tabular}{|c|c|c|c|}
\hline $\begin{array}{c}\text { Degree of patients' } \\
\text { performance of ADL }\end{array}$ & $\begin{array}{c}\text { Study } \\
(\mathbf{n = 3 0})\end{array}$ & $\begin{array}{c}\text { Control } \\
(\mathbf{n = 3 0})\end{array}$ & $\begin{array}{c}\text { Student's t-test } \\
\text { (P value) }\end{array}$ \\
\hline Preoperative & $13.70 \pm 4.09$ & $13.0 \pm 4.35$ & 0.523 \\
\hline Postoperative & $24.47 \pm 3.82$ & $20.97 \pm 2.66$ & $<0.001^{*}$ \\
\hline Paired t-test (P value) & $<0.001^{*}$ & $<0.001^{*}$ & \\
\hline
\end{tabular}

Table 4: mean score, standard deviation and statistical differences between both study and control groups in relation to their psychological status

Shows mean score, standard deviation and statistical differences between both study and control groups in relation to their psychological status. The results revealed statistically significant differences between preoperative and post-discharge in the study and control groups (paired t-test $<0.001^{*},<0.001 *$ ). The results also showed that there was a significant difference between study and control groups after discharge. Student's t-test (P-value $<0.001^{*}$. The significant $\mathrm{p}<0.05$.

Table 4: mean score, standard deviation and statistical differences between both study and control groups in relation to their psychological status

\begin{tabular}{|c|c|c|c|}
\hline $\begin{array}{c}\text { Degree of patients' } \\
\text { performance of ADL }\end{array}$ & $\begin{array}{c}\text { Study } \\
(\mathbf{n = 3 0})\end{array}$ & $\begin{array}{c}\text { Control } \\
(\mathbf{n = 3 0})\end{array}$ & $\begin{array}{c}\text { Student's t-test }(\mathbf{P} \\
\text { value) }\end{array}$ \\
\hline Preoperative & $13.70 \pm 4.09$ & $13.0 \pm 4.35$ & 0.523 \\
\hline Postoperative & $24.47 \pm 3.82$ & $20.97 \pm 2.66$ & $<0.001^{*}$ \\
\hline Paired t-test (P value) & $<0.001^{*}$ & $<0.001^{*}$ & \\
\hline
\end{tabular}

Table 5: Mean score, standard deviation and statistical differences between both study and control groups in relation to their social status.

Shows mean score, standard deviation and statistical differences between both study and control groups in relation to their social status. The results revealed statistically significant differences between preoperative and post-discharge in the study and control groups (paired t-test $\left.<0.001^{*},<0.001 *\right)$. The results also showed that there was a significant difference between study and control groups after discharge. Student's t-test (P value $<0.007 *)$. The significant $\mathrm{p}<0.05$.

Table 5: Mean score, standard deviation and statistical differences between both study and control groups in relation to their social status.

\begin{tabular}{|l|c|c|c|}
\hline \multicolumn{1}{|c|}{ Patients' Social status } & $\begin{array}{c}\text { Study } \\
(\mathbf{n = 3 0})\end{array}$ & $\begin{array}{c}\text { Control } \\
(\mathbf{n = 3 0})\end{array}$ & $\begin{array}{c}\text { Student's t-test } \\
(\mathbf{P} \text { value) }\end{array}$ \\
\hline Preoperative & $11.87 \pm 0.51$ & $10.77 \pm 2.01$ & $0.007^{*}$ \\
\hline Postoperative & $4.27 \pm 0.87$ & $5.07 \pm 2.43$ & 0.099 \\
\hline Paired t-test (P value) & $<0.001^{*}$ & $<0.001^{*}$ & \\
\hline
\end{tabular}


Figure 3: patient's perception of both study and control groups of their readiness for discharge

Reveals both groups patients study and control perception of readiness for discharge. The results indicate that the patients of the study group had higher total perception mean score than those of control group $(4.17 \pm 1.05 \& 1.70 \pm 1.12)$ respectively. The perception of patient readiness toward Help might need at home and watch warning signs and symptoms of complication in the study group were $96.7 \%$ by significance $<0.001 *$. Also, the perception of patients toward Stages of progress during first six months was recorded two third $(73.3 \%)$ by significance $<0.001 *$.the difference between the study and control group was significant $\mathrm{t}=8.793 \mathrm{P}<0.001 *$.

Figure 4: Mean score, standard deviation and statistical difference between study and control group regarding compliance in performing selected activities.

Mean score, standard deviation and statistical difference between study and control group regarding compliance in performing selected activities. The results revealed that patients of the study group had $80 \%$ medium compliance behavior post-operative this percentage higher to $83 \%$ high compliance post discharge. While in control group $70 \%$ had medium compliance post discharge. The sign in a post-discharge period was $(<0.001 *)$. The table also indicated that the difference between postoperative and post-discharge in the study and control groups were statistically significant (p-value $<0.001 *$ and $0.033^{*}$ ).

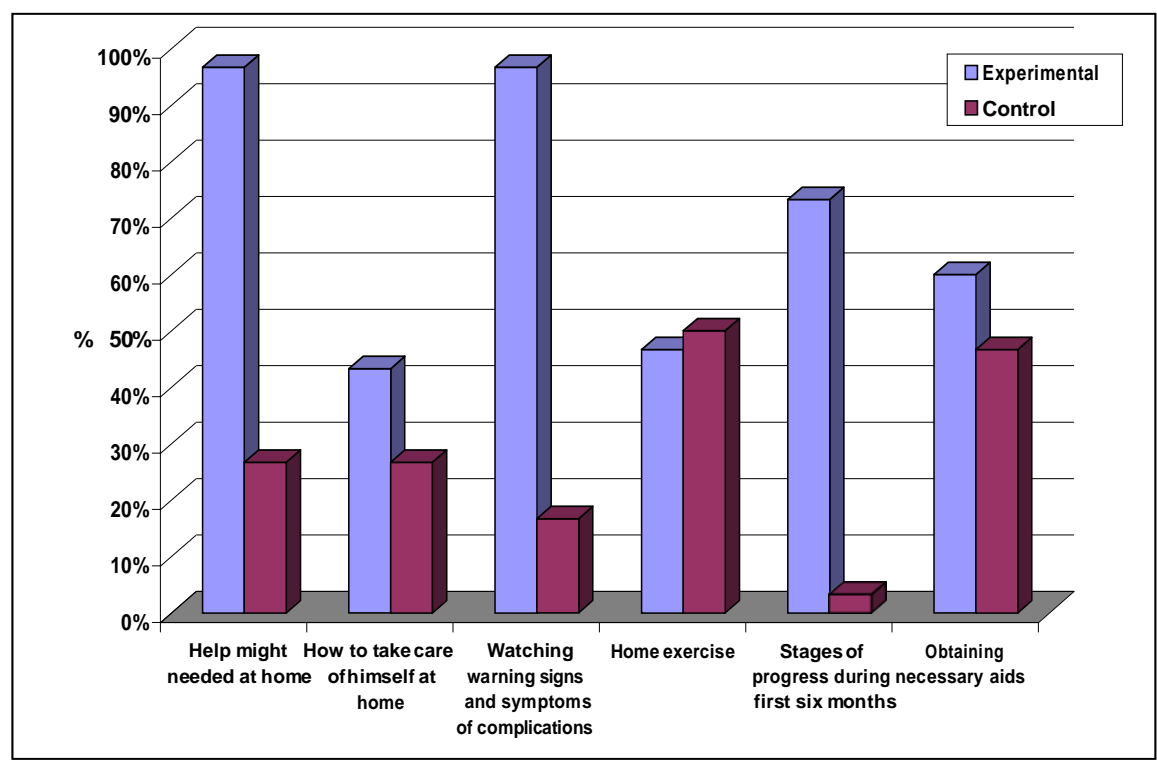

Figure 3: patient's perception of both study and control groups of their readiness for discharge 
Abeer Mohammed el metwaly, et. al.

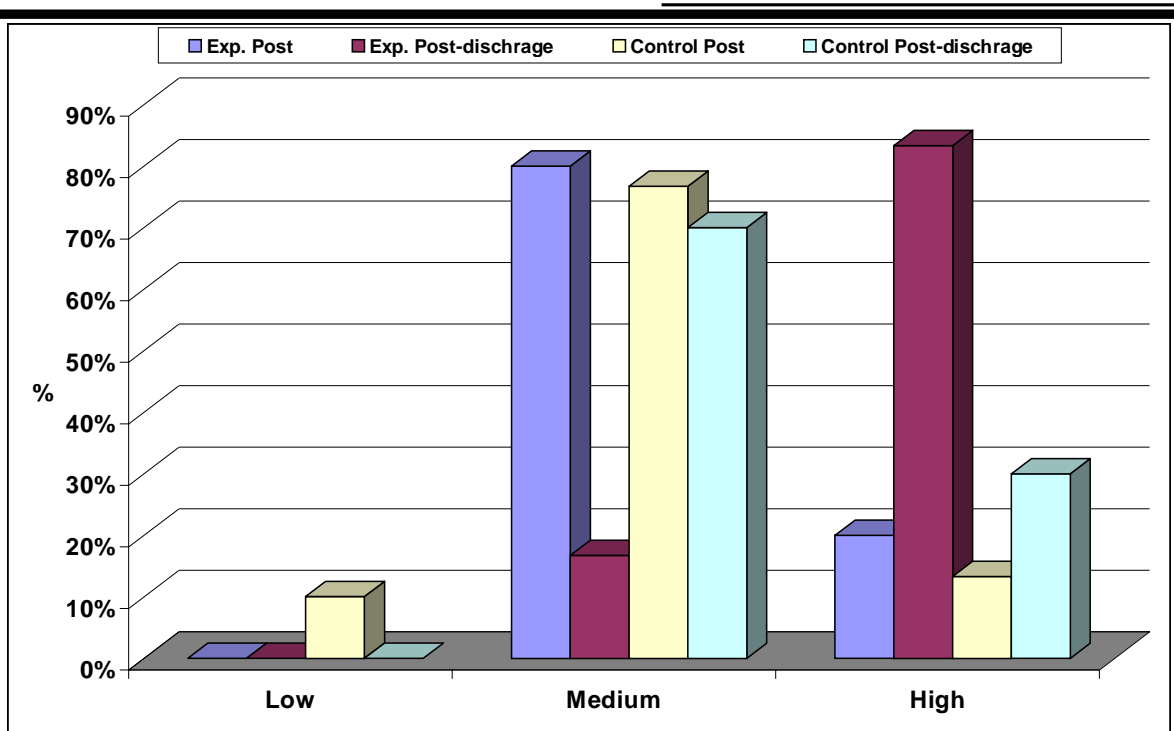

Figure 4 Mean score, standard deviation and statistical difference between study and control group regarding compliance in performing selected activities.

\section{Discussion}

In relation to age, the present study represented that the patient's age ranged between 45-55 years in both study and control groups with mean age 47years. This result is in the same line with ${ }^{(11,12)}$ who mention that total hip replacement patients age are usually 45 to 57 . On the other hand, this result is in disagreement with ${ }^{(13)}$ who presented that THR is more frequent in 65 years and above. The aging population has no doubt contributed to the worldwide increase in THR numbers as age is the strongest predictor of the development and progression of osteoarthritis. On the other hand, this result is in disagreement with (14) who presented that THR is more frequent with younger age.

As regards patients' sex, it was recorded that, the high percentage of the studied patients were females: This finding may be due to the fact that, the females above fifty years are exposed to menopausal hormonal dysfunction which may induce degenerative joint disease. This is in line with ${ }^{(\mathbf{1 5 1 , 6})}$ Rheumatoid arthritis affects two to three times than men with ratio 3:1. In the opposite direction ${ }^{(17)}$ in the opposed side found that most of their studied patients were male ${ }^{(\mathbf{1 8} \text {, }}$ 19)

In relation to the reason for surgical replacement, the majority of sample suffered from osteoarthritis. Series of studies are consistent with this result $\mathbf{( 2 0 , 2 1 )}^{-2}$ On the other hand, this result comes in disagreement with ${ }^{(22)}$ who represented that the reason for surgical replacement was osteoporosis caused by medications; as corticosteroid therapy and osteoporosis are independent risk factors for cartilage degeneration at the femoral head ${ }^{(\mathbf{2 3})}$

According to an assessment of patients with operated hip, findings of this study showed a significant improvement post discharge than preoperative for patients in both study and control groups in relation to objective functional capability index these in the same line with $(\mathbf{1 0 , 2 4 )}$. who mention that the effectiveness of post-discharge exercises physiotherapy program the establishment function and quality out com. 
This result reported that patient who can't ambulate preoperative for many years because of pain, limitation of range of motion, weakness of muscles improved post-discharge and able to do this is agree with many studies that reported the better physical functional outcomes after THR within six to eight weeks, three months rehabilitation physiotherapy measured improving range of motion, strength and gait speed, walking ability, decrease joint discomfort are improved after THR so improving function and quality of life ( 25,26).

As regards patients' ability to perform indoor and outdoor activities of daily living as an indicator of subjective functional capabilities, the results revealed that reliance on others for help was significantly lower post discharge than on admission for all studied patients. This reliance on others was concerning wearing clothes, bathing, and house chores. This result is in the same line with ${ }^{(27)}$. It indicated that patients received assistance with few activities after surgery. The surgical treatment was effective in reducing the burden of indoor activities on caregivers.

The present findings also showed that after discharge patients of the study group demonstrated significantly higher psychological capabilities than the control group of patients. This result may be related to the role of the rehabilitation program that explains stages of patient's progress and how to deal with posthospital difficulties. This finding was in congruence with many research studies that pointed to the critical role of information in permitting patients to adapt to stress or illness, in reducing anxiety and learning to cope with residual disability and in promoting recovery ${ }^{(28)}$

It is exciting that both study and control group patients reported the reduction in anxiety post-discharge period. This reduction in anxiety and distress may be associated with the decrease in pain following the total hip replacement surgery. This result is in accordance with those reported by (28) who found that anxiety and pain were significantly reduced after surgery and increasing patient satisfaction and improving function outcome this agree with ${ }^{(29)}$

\section{Conclusion:}

Based on the findings of the present study the following can be concluded that:

1- The rehabilitation program that was applied to study group of total hip replacement had the positive effect on function out com including in-outdoor activities.

2- The booklet was given to patients before discharge helped to reach the high level of compliance and redness for hospital discharge.

\section{Recommendations:}

1- Rehabilitation program should be started on the first day of patient admission to hospital.

2-the booklet should be available for each patient undergoing total hip replacement surgery.

3-Nurses working in orthopedic unites should update their knowledge through training programs.

4-The nursing school program of study should include nursing role in rehabilitation

\section{Conflict of interest:}

The authors declare that they have no conflict of interest

\section{Acknowledgments:}

We deem it necessary to thank all professors, the respective employees, and nurses of orthopedic department and outpatient clinic, as well as patients who helpfully responded to the questionnaires. 


\section{Reference : \\ 1- Wilk-Frańczuk, M. (2012). \\ Rehabilitation of Patients Following \\ Arthroplasty of the Hip and Knee. In \\ Recent Advances in Hip and Knee \\ Arthroplasty. Book edited by Samo \\ K. Foster, ISBN 978-953-307-841-0, \\ Published: January 27, 2012, under \\ CC-BY 3.0 license.}

2- Okoro, T., Lemmey, A., Maddison, P., \& Andrew, J. (2012). An appraisal of replacement surgery. rehabilitation regimes used for improving functional outcome after total hip reports Medicine, Arthroscopy, Rehabilitation, Therapy \& Technology, 4(1), 5.

3- Organization for Economic Cooperation and Development countries [OECD] (2016), Health at a Glance: Europe 2012, OECD Publishing, Paris. DOI: http://dx.doi.org/10.1787/978926418 3896-en.

4 Rupasov, A., Cain, U., Montoya, S., \& Blickman, J. (2017). Imaging of Posttraumatic Arthritis, Avascular Necrosis, Septic Arthritis, Complex Regional Pain Syndrome, and Cancer Mimicking Arthritis. Radiologic Clinics of North America. Volume 55, Issue 5, Pages 1111-1130

5- Maradit Kremers, H., Larson, D. Crowson, C., Kremers, W., Washington, R. E., Steiner, C. A., Berry, D. J. (2015). Prevalence of Total Hip and Knee Replacement in the United States. The Journal of Bone \& Joint Surgery, 97(17), 13861397.

http://doi.org/10.2106/JBJS.N.01141

6- Hunter, T. B., Taljanovic, M. S., Wild, J. R., \& Scalcione, L. (Eds.). (2017). Radiologic Guide to Orthopedic Devices. Cambridge University Press.
7- Aziz, Basem, Neil Patel, and Miksha Patel. "21: Rehabilitation Following Total Knee Arthroplasty and Total Hip Arthroplasty." Physical Medicine and Rehabilitation Patient-Centered Care: Mastering the Competencies (2014): 248.

8- Macchiaroli, J. M. (2012). Relationships between pre-operative education, patient self-efficacy, patient anxiety, body mass index, and patient satisfaction of geriatric patients receiving a primary total hip or total knee arthroplasty. Dowling College.

9- Wong, J., Wong, S., Nolde, T. and Yabsley, R.H., (1990). Effects of an experimental program on the posthospital adjustment of early discharged patients. International Journal of Nursing Studies, 27(1), pp.7-20.

10- Coulter, C., Scarvell, ., Neeman M ., \& Smith, P. N. (2013).

Physiotherapist-directed rehabilitation exercises in the outpatient or home setting improve strength, gait speed, and cadence after elective total hip replacement: a systematic review. Journal of physiotherapy, 59(4), 219-226.

11- Avram, V., Petruccelli, D., Winemaker, M. and de Beer, J., 2014. Total joint arthroplasty readmission rates and reasons for 30 day hospital readmission. The Journal of Arthroplasty, 29(3), pp.465-468.

12- Wong E. hip replacement surgery journal of advanced nursing 2005:12,28-32

13- Smith, G. H., Johnson, S. Ballantyne, J. A., Dunstan, E., \& Brenkel, I. J. (2012). Predictors of excellent early outcome after total hip arthroplasty. Journal of Orthopaedic Surgery and Research, 
7, 13. https://doi.org/10.1186/1749799X-7-13

14 W-Dahl, A., Robertsson, O., \& Lidgren, L. (2010). Surgery for knee osteoarthritis in younger patients: A Swedish Register Study. Acta Orthopaedica, 81(2), 161-164. http://doi.org/10.3109/174536709034 13186

15- Liu, S. S., Buvanendran, A., Rathmell, J. P., Sawhney, M., Bae, J., Moric, M., Sculco, T. P. (2012). Predictors for moderate to severe acute postoperative pain after total hip and knee replacement. International Orthopaedics, 36(11), 2261-2267.

http://doi.org/10.1007/s00264-0121623-5

16- Stark, A. J. (2016). Empowering knowledge and Quality of Recovery after hip or knee replacement. (Doctoral dissertation, Linköping University). ISSN 0345-0082. ISBN 978-91-7685-876-9

17- 15-Silman J, Pearson E (2009). Arthritis research: Epidemiology and genetics of rheumatoid arthritis:4(3):265-72.

18- 16 Madadi, F., Eajazi, A., Kazemi, S. M., Aalami Harandi, A., Madadi, F., \& Sharifzadeh, S. R. (2011). Total hip arthroplasty in advanced osteonecrosis: the short-term results by metal-on-metal hip resurfacing. Medical Science Monitor : International Medical Journal of Experimental and Clinical Research, 17(2), 78-82.

19- Thomas, K., Barrett, B., Tupper, R., Dacenko-Grawe, L., \& Holm, K. (2014). Pain Management After Total Knee Arthroplasty: A Case-Control Study of Continuous Nerve Block Therapy. Orthopaedic Nursing, 33(5), 268-276.
http://doi.org/10.1097/NOR.0b013e3 $182879 \mathrm{bd} 9$

20- Keurentjes, J., Van Tol, F., Fiocco, M., So-Osman, C., Onstenk, R., Koopman-Van Gemert, A. Nelissen, (2014). Patient acceptable symptom states after total hip or knee replacement at mid-term follow-up: Thresholds of the Oxford hip and knee scores. Bone \& Joint Research, $3(1)$, 7-13. http://doi.org/10.1302/20463758.31.2000141

21- Lenguerrand, E., Wylde, V., Gooberman-hill, R., Sayers, A., Brunton, L., Beswick, A., Blom, A. W. (2016). Trajectories of Pain and Function after Primary Hip and Knee Arthroplasty : The ADAPT Cohort Study, PLoS ONE 11(2): 1-16. http://doi.org/10.1371/journal.pone.0 149306

22- Balasubramanian, A., Tosi, L., Lane, J., Dirschl \& Malley, C. (2014). Declining rates of osteoporosis management following fragility fractures in the U.S., 2000 through 2009. Journal of Bone and Joint Surgery - Series A, 96(7), 1-8. http://doi.org/10.2106/JBJS.L.01781

23- Hagiwara, S., Nakamura, J., Watanabe, A., Kishida, S., Ohtori, S., Omae, T., Takahashi, K. (2015). Corticosteroids and low bone mineral density affect hip cartilage in systemic lupus erythematosus patients: Quantitative T2 mapping. Journal of Magnetic Resonance Imaging : JMRI, 42(6), 1524-1531. http://doi.org/10.1002/jmri.24953

24- Holm, Bente, et al. "Surgery-induced changes and early recovery of hipmuscle strength, leg-press power, and functional performance after fasttrack total hip arthroplasty: a prospective cohort study." PloS one 8.4 (2013): e62109. 
25- Carmeli, E., Sheklow, S. , \& Coleman, R. (2006). A comparative study of organized class-based exercise programs versus individual home-based exercise programs for elderly patients following hip surgery. Disability and rehabilitation, 28(16), 997-1005.

26- Beaulieu, L., \& Beaule, P. E. (2011). Comparison of Joint Mechanics of Both Lower Limbs of THA Patients with Healthy Participants during Stair Ascent and Descent, (March), 305-311.

https://doi.org/10.1002/jor.21248

27- SAMPSON, Brittany Anne. (2016) Patient Outcomes Following Hip and Knee Joint Replacement Surgery: Role of the Social and Physical Environment in Recovery. 2016
28- Tristaino.V ,Lantieri .F ,Torango. Gramazio .M (2015). The effectiveness of psychological support in patients undergoing primary total hip or knee arthroplasty: a controlled cohort study. Journal of Orthopaedics and Traumatology, 17(2), 137-147. https://doi.org/10.1007/s10195-0150368-5

29- Hossain, M., Parfitt, D., Beard, D. , Darrah, C., Nolan, J., Murray, D. , \& Andrew, G. (2011). Does preoperative psychological distress affect patient satisfaction after primary total hip arthroplasty? BMC Musculoskeletal Disorders, 12, 122. https://doi.org/10.1186/1471-2474$\underline{12-122}$ 